\title{
Contrasting effects of preexisting hyperglycemia and higher body size on hospital mortality in critically ill patients: a prospective cohort study
}

\author{
Marina Verçoza Viana ${ }^{1 *}{ }^{*}$, Rafael Barberena Moraes ${ }^{1 \dagger}$, Amanda Rodrigues Fabbrin $^{2 \dagger}$, Manoella Freitas Santos ${ }^{2 \dagger}$, \\ Vanessa Bielefeldt Leotti Torman ${ }^{3 \dagger}$, Silvia Regina Vieira ${ }^{1+}$, Jorge Luiz Gross ${ }^{2+}$, Luis Henrique Canani ${ }^{2+}$ \\ and Fernando Gerchman ${ }^{2+}$
}

\begin{abstract}
Background: Obesity and diabetes mellitus are well-defined risk factors for cardiovascular mortality. The impact of antecedent hyperglycemia and body size on mortality in critical ill patients in intensive care units (ICUs) may vary across their range of values. Therefore, we prospectively analyzed the relationship between in-hospital mortality and preexisting hyperglycemia and body size in critically ill ICU patients to understand how mortality varied among normal, overweight, and obese patients and those with low, intermediate, and high glycated hemoglobin $\left(\mathrm{HbA}_{1 \mathrm{c}}\right)$ levels.

Methods: Medical history, weight, height, physiologic variables, and $\mathrm{HbA}_{1 \mathrm{c}}$ were obtained during the first $24 \mathrm{~h}$ for patients who were consecutively admitted to the high complexity ICU of Hospital de Clínicas de Porto Alegre, Brazil, from April to August 2011. The relationships between mortality and obesity and antecedent hyperglycemia were prospectively analyzed by cubic spline analysis and a Cox proportional hazards model.

Results: The study comprised 199 patients. The overall hospital mortality rate was 43.2\% during a median 16 (8-28) days of follow-up. There was a progressive risk of in-hospital mortality with higher $\mathrm{HbA}_{1 c}$ levels, with the relationship becoming significant at $\mathrm{HbA}_{1 c}>9.3 \%$ compared with lower levels (hazard ratio 1.74; $95 \%$ confidence interval with Bonferroni correction 1.49-2.80). In contrast, mean body mass index (BMI) was higher in survivors than in nonsurvivors $\left(27.2 \mathrm{~kg} / \mathrm{m}^{2} \pm 7.3\right.$ vs. $24.7 \mathrm{~kg} / \mathrm{m}^{2} \pm 5.0 P=0.031$, respectively). Cubic spline analysis showed that these relationships differed nonlinearly through the spectrum of BMI values. In a Cox proportional hazards model adjusted for Acute Physiology and Chronic Health Evaluation II score and $\mathrm{HbA}_{1,}$, the risk of in-hospital mortality progressively decreased with increasing BMI (BMI $<20$ vs. $20-23.9 \mathrm{~kg} / \mathrm{m}^{2}, P=0.032 ; \mathrm{BMl}<20$ vs. $24-34.9 \mathrm{~kg} / \mathrm{m}^{2}, P=0.010 ; \mathrm{BMl}<20$ vs. $\geq 35 \mathrm{~kg} / \mathrm{m}^{2}, P=0.032$ ).
\end{abstract}

Conclusions: Our findings suggest that significant hyperglycemia prior to ICU admission is a risk factor for in-hospital mortality. Conversely, increasing BMI may confer an advantageous effect against mortality in critical illness independently of previous glycemic control.

Keywords: Diabetes mellitus, Glycated hemoglobin, Obesity, Intensive care unit, Mortality

\footnotetext{
* Correspondence: marivv@terra.com.br

'Equal contributors

'Intensive Care Unit, Division of Endocrinology, Hospital de Clínicas de Porto

Alegre, Federal University of Rio Grande do Sul, Porto Alegre, Brazil

Full list of author information is available at the end of the article
} 


\section{Background}

Diabetes mellitus (DM) and obesity are well-defined risk factors for cardiovascular disease and mortality [1,2]. Both diseases have assumed epidemic proportions in the last few decades $[1,3]$. As a consequence, the increasing rates of admission of patients with obesity and/or DM to intensive care units (ICUs) have become a concern for intensivists [4].

A large body of evidence has defined poor glycemic control as a negative prognostic factor in critical illness $[5,6]$. This association is especially true in patients without a past known history of DM, but is poorly defined in those with known DM [7-9]. It is also unclear how glycemic control before ICU admission affects prognosis in critically ill patients.

The measurement of glycated hemoglobin $\left(\mathrm{HbA}_{1 \mathrm{c}}\right)$ levels is widely employed to estimate average glucose levels over a 2- to 3-month period, providing a method for the assessment of past glycemic control [10]. Recently, the American Diabetes Association (ADA) proposed the use of $\mathrm{HbA}_{1 \mathrm{c}}$ levels for the diagnosis of prediabetes and DM [11]. Because $\mathrm{HbA}_{1 \mathrm{c}}$ reflects past glycemic control, it can be used to understand the relationship between prior hyperglycemia and morbidity and mortality in recently admitted critically ill patients $[10,11]$. Recent data have linked higher $\mathrm{HbA}_{1 \mathrm{c}}$ levels to increased ICU mortality [12].

Obesity is considered a risk factor for the development of DM $[1,3]$. The impact of obesity as a prognostic factor in critically ill patients is controversial, and possibly influenced by the presence of DM [13]. Findings to date are not conclusive, with some studies reporting no association between obesity and mortality $[14,15]$, and others finding that low body mass index (BMI) is associated with increased mortality [15-17], or that excess weight is a negative prognostic factor $[18,19]$. Two meta-analyses pooling data on studies evaluating the impact of obesity on outcomes in ICU patients did not find an association between obesity and mortality in critical illness [20,21].

However, data analyzing the effect of glycemic status and body size on survival in ICU patients across the spectrum of body size and glycemic status may give the opportunity to better understand the complex relationship between hyperglycemia, excess weight, and survival in critical illness. To address this issue, we investigated whether preexisting hyperglycemia and body size are determinants of morbidity and mortality in patients recently admitted to the ICU.

\section{Methods}

\section{Study design}

This was a prospective observational study carried out in the ICU of Hospital de Clínicas de Porto Alegre, an 850-bed teaching hospital of Federal University of Rio Grande do Sul, Brazil. Written informed consent was obtained from each participant (or surrogate), and the study was approved by Research Ethics Committee of Hospital de Clínicas de Porto Alegre. No patients (or surrogate) refused to participate in the study.

\section{Study population and data source}

Consecutive medical and surgical patients aged $\geq 18$ years who were first admitted to the ICU between April 1, 2011, and August 22, 2011, were eligible for inclusion. Patients with hyperglycemic crisis (diabetic ketoacidosis or hyperosmolar hyperglycemic states) and those with hemoglobinopathies were excluded.

Clinical and demographic data were collected at baseline, including a detailed past medical history, data regarding corticosteroid and vasopressor therapy, mechanical ventilation support, and renal replacement therapy. Physiologic and laboratory data were collected for calculation of Acute Physiology and Chronic Health Evaluation (APACHE) II and Sequential Organ Failure Assessment (SOFA) scores $[22,23]$. Supine height $(\mathrm{cm})$ and weight $(\mathrm{kg})$, as measured routinely on ICU admission, were used to calculate BMI, expressed as weight $(\mathrm{kg}) /$ height $^{2}(\mathrm{~m})$.

Glucose (hexokinase assay), ultrasensitive C-reactive protein (enzymatic colorimetric assay), lactate (turbidimetric method), and $\mathrm{HbA}_{1 \mathrm{c}}$ (high-performance liquid chromatography using Tosoh 2.2 Plus $\mathrm{HbA}_{1 \mathrm{c}}$; Tosoh Corporation, Tokyo, Japan) were measured within $24 \mathrm{~h}$ of ICU admission. The $\mathrm{HbA}_{1 \mathrm{c}}$ method was certified by the National Glycohemoglobin Standardization Program (NGSP) (http://www.ngsp.org/critsumm.asp) and values were International Federation of Clinical Chemistry and Laboratory Medicine (IFCC)-aligned. The Hospital de Clínicas de Porto Alegre Clinical Pathology Department is a participant in and meets the standards of the $\mathrm{HbA}_{1 \mathrm{c}}$ external quality assurance program [24].

Based on $\mathrm{HbA}_{1 \mathrm{c}}$ levels, patients were categorized according to ADA criteria as having normal glucose tolerance ( $<5.7 \%)$, prediabetes (5.7-6.4\%), or DM ( $\geq 6.5 \%)$ [11]. Patients with a known history of DM were classified as having DM regardless of $\mathrm{HbA}_{1 \mathrm{c}}$ levels. Patients were divided into four BMI categories, according to World Health Organization definitions: underweight (BMI $<18.5 \mathrm{~kg} / \mathrm{m}^{2}$ ), normal weight (BMI $18.5-24.9 \mathrm{~kg} / \mathrm{m}^{2}$ ), overweight (BMI $25-29.9 \mathrm{~kg} / \mathrm{m}^{2}$ ), class I and II obesity (BMI $30-39.9 \mathrm{~kg} /$ $\mathrm{m}^{2}$ ), and extreme obesity $\left(\mathrm{BMI}>40 \mathrm{~kg} / \mathrm{m}^{2}\right)[25]$.

\section{Data analysis and statistical methods}

Statistical analyses were performed using PASW Statistics 18 and R 2.13.2 (R Foundation for Statistical Computing, Vienna, Austria). Data are presented as means \pm standard deviation, median (interquartile range), or absolute and relative frequencies (\%). To compare demographic, clinical and laboratory data, the Student $t$-test for independent samples, Mann-Whitney U, or chi-square tests were used 
as appropriate. Correlations were assessed with the Pearson or Spearman correlation coefficients. Kaplan-Meier eventfree survival curves were used to compare the probability of in-hospital mortality according to different BMI strata. Cox regression models and the additional fit of cubic splines with four knots were used as exploratory data analysis for visual assessment of the functional relationship between $\mathrm{BMI}, \mathrm{HbA}_{1 \mathrm{c}}$ and mortality while adjusting for APACHE II score [26-28]. The tested cutoff points for BMI were from 20 to 35 , with increments of 0.5 . For each increment, the study sample was divided into two groups defined by being lower or higher than the cutoff point and Cox proportional hazards models were used to estimate the risk of in-hospital mortality (dependent variable) for each stratum. The spline was then adjusted with the estimated risks to provide a better understanding of the relationship with $\mathrm{BMI}$ and $\mathrm{HbA}_{1 \mathrm{c}}$ levels. In addition, 95\% confidence intervals for the fitted curve were calculated with a Bonferroni correction. A two-tailed $P$ value $<0.05$ was considered significant.

\section{Results}

\section{Patient profile}

The study group comprised 199 patients, of whom 111 (55.8\%) were men and $88(44.2 \%)$ were women. The overall in-hospital mortality rate was $43.2 \%$ during a median of 16 (8-28) days of follow-up. Table 1 lists the characteristics of all study patients and compares survivors and nonsurvivors. The two groups did not differ regarding gender, comorbidities, history of DM, glucose tolerance, or $\mathrm{HbA}_{1 \mathrm{c}}$ levels. The number of days in hospital prior to ICU admission, APACHE and SOFA scores and plasma lactate levels, as well as the proportion of patients requiring mechanical ventilation, hemodialysis and vasopressor support, were higher among nonsurvivors than among survivors. Age and C-reactive protein levels also tended to be higher, while BMI was lower in nonsurvivors in comparison to survivors.

A total of 149 (74.9\%) patients had no known history of DM. However, a significant proportion of these seemed to have previously abnormal glucose metabolism (51 [34.2\%] with prediabetes and 16 [10.7\%] with DM). BMI was indicative of normal weight in $43.7 \%$ of patients. Excess weight was observed in $50.3 \%$ of the sample $(33.1 \%$ overweight, $13.2 \%$ obese, and $4 \%$ extremely obese), whereas $6 \%$ were underweight.

\section{Relationship between glycemic control before ICU} admission, total hemoglobin, body size, and prognostic factors for mortality

Because the relationship between $\mathrm{HbA}_{1 \mathrm{c}}$ and mortality could be confounded by BMI, anemia or other factors, the correlations of $\mathrm{HbA}_{1 \mathrm{c}}$ with total hemoglobin, BMI, and severity scores were analyzed. There was a weak
Table 1 Clinical and laboratory characteristics according to survival

\begin{tabular}{lccc}
\hline & $\begin{array}{c}\text { Survivors } \\
(\mathbf{n = 1 1 3})\end{array}$ & $\begin{array}{c}\text { Nonsurvivors } \\
(\mathbf{n = 8 6 )}\end{array}$ & $\mathbf{P}$ \\
\hline Age (years) & $56 \pm 17.4$ & $61 \pm 17$ & 0.052 \\
Males & $65(57.5)$ & $46(53.5)$ & 0.570 \\
$\begin{array}{l}\text { Days in hospital before } \\
\text { ICU admission }\end{array}$ & $2.5(1-8)$ & $6(1-16)$ & $<0.00$ \\
APACHE II & $17.6 \pm 7.9$ & $24.8 \pm 7.8$ & $<0.00$ \\
SOFA & $5(2-9)$ & $8(6-13)$ & $<0.00$
\end{tabular}

Comorbidities

$\mathrm{CHF}$

$12(10.8)$

$9(10.5)$

0.938

HIV

$6(5.4)$

$7(8.1)$

0.443

Body mass index $\left(\mathrm{kg} / \mathrm{m}^{2}\right)$

$27.2 \pm 7.3$

$24.7 \pm 5$

0.031

History of DM

$26(23)$

$24(27.9)$

0.430

Glucose tolerance

Normal

$51(45.1)$

0.359

Prediabetes

40 (35.4)

$41(47.7)$

Diabetes

$22(19.5)$

$23(26.7)$

$22(25.6)$

$\mathrm{HbA}_{1 c}(\%)$

$5.7(5.3-6.3)$

$5.8(5.2-6.5)$

0.729

Serum glucose $(\mathrm{mg} / \mathrm{dL})$

Lactate $(\mathrm{mg} / \mathrm{dL})$

$122(99-160)$

$120(95-167)$

0.909

C-reactive protein $(\mathrm{mg} / \mathrm{dL})$

$9.0(6.3-15.3)$

$18(0-35)$

$<0.001$

Mechanical ventilation

$87(27.5-150.4)$

$102(44-234)$

0.067

Hemodialysis

$69(61.1)$

68 (79.1)

0.008

Vasopressor support

15 (13.3)

$30(34.9)$

$<0.001$

Data are expressed as mean \pm standard deviation, median (interquartile range) or $\mathrm{n}(\%)$. COPD, chronic obstructive pulmonary disease; $\mathrm{CHF}$, congestive heart failure; HIV, human immunodeficiency virus. To convert glucose from $\mathrm{mg} / \mathrm{dl}$ to $\mathrm{mmol} / \mathrm{L}$, multiply by the factor 0.005 . To convert lactate from $\mathrm{mg} / \mathrm{dL}$ to $\mathrm{mmol} / \mathrm{L}$, multiply by the factor 0.111 .

correlation of $\mathrm{HbA}_{1 \mathrm{c}}$ with hemoglobin levels $\left(\mathrm{r}^{2}=0.026\right.$; $P=0.025)$ and BMI $\left(\mathrm{r}^{2}=0.05 ; P=0.007\right) . \mathrm{HbA}_{1 \mathrm{c}}$ was not related to plasma lactate $\left(\mathrm{r}^{2}=0.01 ; P=0.135\right)$ or $\mathrm{C}$ reactive protein levels $\left(\mathrm{r}^{2}<0.01 ; P=0.050\right)$, nor to APACHE II $\left(\mathrm{r}^{2}<0.01 ; P=0.958\right)$ and SOFA scores $(\mathrm{r}=0.01$; $P=0.449$ ).

Body size, as estimated by BMI, was also not related to plasma lactate $\left(\mathrm{r}^{2}<0.01 ; P=0.352\right)$, C-reactive protein $\left(r^{2}=0.01 ; P=0.196\right)$, APACHE II $\left(r^{2}<0.01 ; P=0.334\right)$, or SOFA $\left(\mathrm{r}^{2}<0.01 ; P=0.634\right)$ scores.

\section{Relationship between $\mathrm{HbA}_{1 \mathrm{c}}$, body size and morbidity}

Using $\mathrm{HbA}_{1 \mathrm{c}}$ to classify patients as having normal glucose tolerance, prediabetes, or DM, we were able to analyze whether increasingly abnormal glucose metabolism was related with increasing ICU morbidity. There were no glucose metabolism-related differences in the need for mechanical ventilation (normal vs. prediabetes vs. $\mathrm{DM}, P=0.894$ ), vasopressor support (normal vs. prediabetes vs. DM, $P=0.460$ ), 
or renal replacement therapy (normal vs. prediabetes vs. DM, $P=0.583$ ). These requirements also did not differ from the lowest to the highest BMI strata.

\section{Relationship between chronic glycemic control, body size,} and mortality

There was no difference in $\mathrm{HbA}_{1 \mathrm{c}}$ levels between survivors and nonsurvivors (Table 1). When only the subgroup of patients with a known history of DM were analyzed, there was also no difference in $\mathrm{HbA}_{1 \mathrm{c}}$ levels between survivors and nonsurvivors $(6.70 \%$ [5.8-8.5] vs. 6.8\% [5.9-8.1]; $P=0.846$ ).

Cubic spline analysis was used to better analyze the relationship between $\mathrm{HbA}_{1 \mathrm{c}}$, $\mathrm{BMI}$, and hospital mortality during follow-up. This statistical approach enabled graphical quantification of how the risk of hospital mortality (expressed as hazard ratio [HR]) varied across different $\mathrm{HbA}_{1 \mathrm{c}}$ and BMI levels. The risk of hospital mortality was significantly increased in patients with $\mathrm{HbA}_{1 \mathrm{c}}$ levels $\geq 9.3 \%$ compared with those with lower $\mathrm{HbA}_{1 \mathrm{c}}$ levels (Figure 1). Nevertheless, the relationship between BMI and risk of hospital mortality was nonlinear. Patients with a BMI between 24 and $30 \mathrm{~kg} / \mathrm{m}^{2}$ did not exhibit increased hospital mortality (Figure 2). In-hospital mortality was higher among those with BMI in the $20-24 \mathrm{~kg} / \mathrm{m}^{2}$ range and lower among those with BMI $>30 \mathrm{~kg} / \mathrm{m}^{2}$. For example, at lower body sizes, patients with BMI $<23 \mathrm{~kg} / \mathrm{m}^{2}$ had a $40 \%$ higher risk of in-hospital mortality $(\mathrm{HR}=1.4)$ as compared with those with $\mathrm{BMI} \geq 23 \mathrm{~kg} / \mathrm{m}^{2}$. In patients with

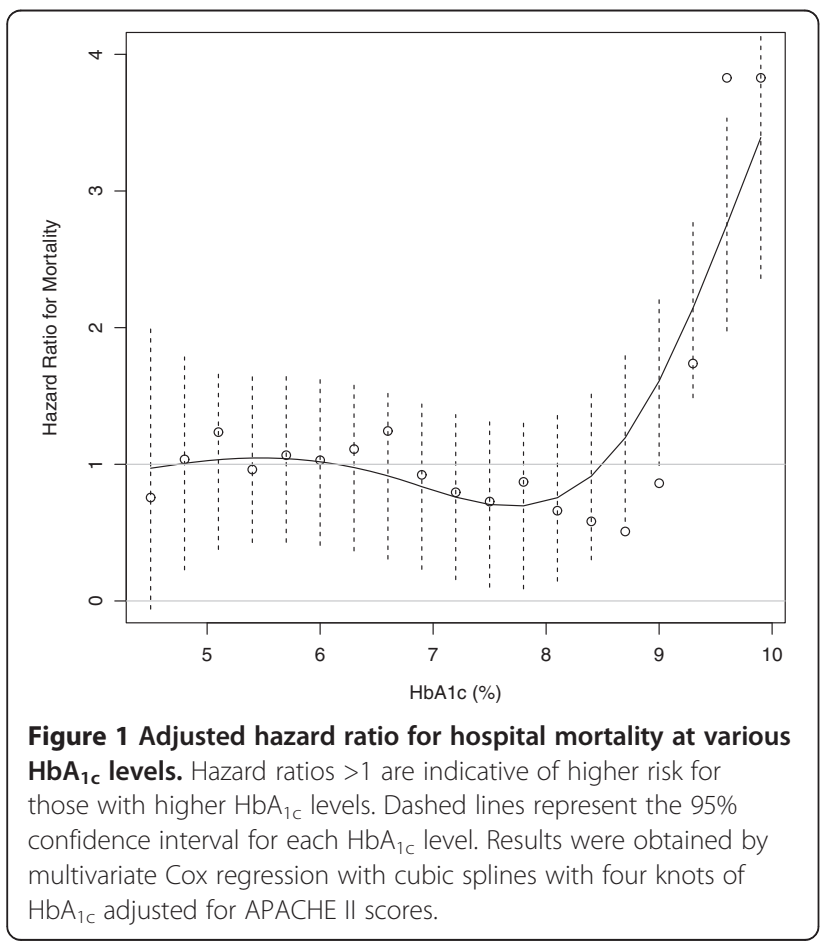

higher body size, those with BMI $<33 \mathrm{~kg} / \mathrm{m}^{2}$ had twice the risk of in-hospital mortality $(\mathrm{HR}=2.0)$ compared with those with BMI $\geq 33 \mathrm{~kg} / \mathrm{m}^{2}$. The lowest in-hospital mortality was observed among the patients with the highest BMIs (Figure 2).

Based on these findings (Figure 2), we stratified the study sample into four groups by BMI (group 1 , BMI $<20 \mathrm{~kg} / \mathrm{m}^{2}$; group 2, 20-23.9 kg/m²; group 3, 24-34.9 $\mathrm{kg} / \mathrm{m}^{2}$; group $4, \geq 35 \mathrm{~kg} / \mathrm{m}^{2}$ ) and compared them by multivariate Cox regression analysis. In comparison with group 1 , mortality progressively decreased with increasing $\mathrm{BMI}$ while adjusting for $\mathrm{HbA}_{1 \mathrm{c}}$ and APACHE II score $(P=0.032$; Figure 3).

\section{Discussion}

Our findings suggest a nonlinear relationship between glycemic control before ICU admission, body size, and in-hospital mortality. The risk of the in-hospital mortality significantly increases with $\mathrm{HbA}_{1 \mathrm{c}}$ levels above $9.3 \%$. It also progressively increases in patients with a BMI below $24 \mathrm{~kg} / \mathrm{m}^{2}$, having no association with mortality in overweight patients, while progressively declining in those with a BMI above $35 \mathrm{~kg} / \mathrm{m}^{2}$. The weak correlation between $\mathrm{HbA}_{1 \mathrm{c}}$ and $\mathrm{BMI}$ suggests an independent effect of these metabolic parameters as prognostic factors in critically ill patients.

Previous studies suggest that increased $\mathrm{HbA}_{1 \mathrm{c}}$ levels are a negative prognostic marker in patients with $\mathrm{DM}$ admitted to an ICU [12]. As DM is usually asymptomatic in its early stages, many patients may not be aware of this condition on ICU admission [29]. In our sample, $44.9 \%$ of participants with abnormal glucose metabolism had no previous history of prediabetes or DM. In a retrospective study, preexisting hyperglycemia affected the relationship between acute blood glucose levels and mortality, suggesting a significant interaction between chronic and acute glycemic control [9]. In our study using Cox regression models incorporating a cubic spline with four knots, we were able to detect an increased risk of mortality in those with significant hyperglycemia $\left(\mathrm{HbA}_{1 \mathrm{c}}\right.$ above 9.3\%). However, in the retrospective study, $\mathrm{HbA}_{1 \mathrm{c}}$ levels $>7.0 \%$ with less stringent glycemic control were associated with decreased mortality [9].

Although our data do not suggest that body size interacts with past glycemic control to determine hospital mortality, BMI was significantly associated with mortality. Our findings confirm those of other studies that suggest an inverse relationship between body size and mortality in critically ill patients $[15,16,30,31]$. We analyzed whether this finding could be explained by other factors such as the requirement for mechanical ventilation, renal replacement therapy or vasopressor support, and our data suggest the $\mathrm{BMI} /$ mortality relationship is independent of these interventions. 


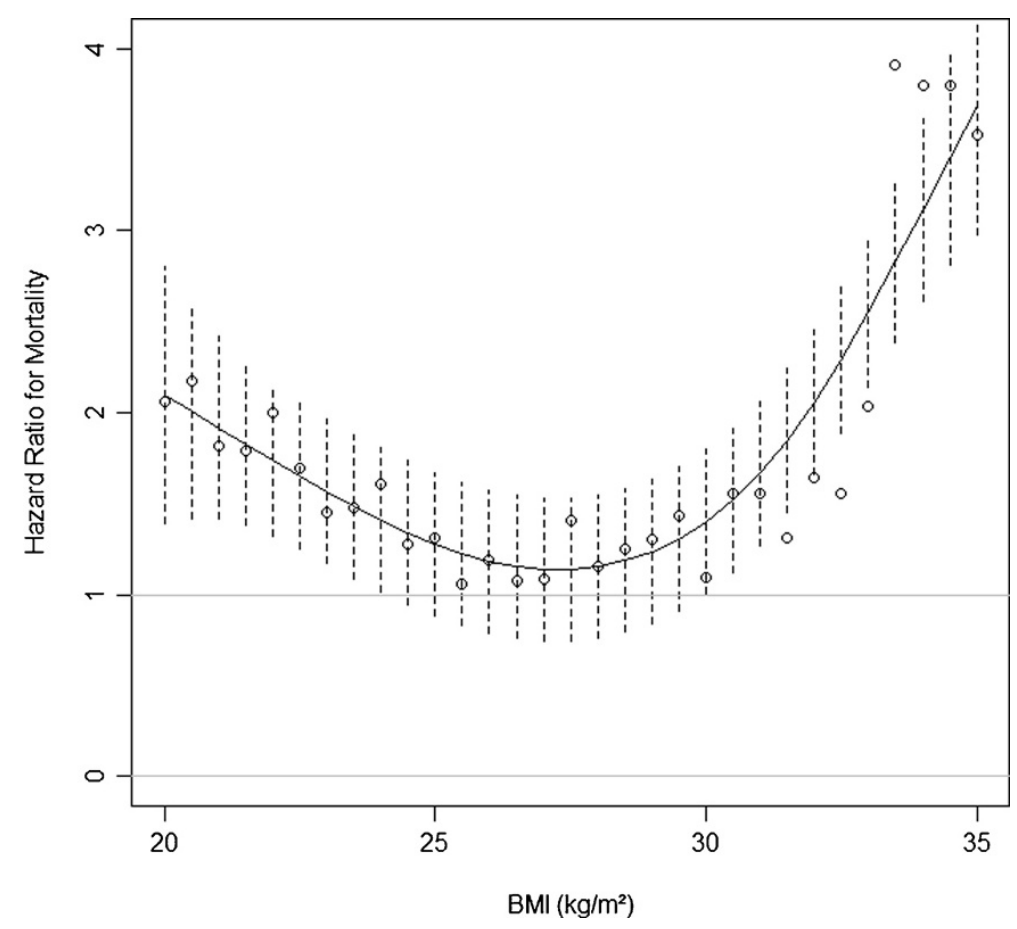

Figure 2 Adjusted hazard ratio at various BMI levels. The risk of hospital mortality is found when the hazard ratio expressed as mean (empty circle) and $95 \%$ confidence interval (dashed lines) do not cross 1. A hazard ratio $>1$ is indicative of increased risk for those with BMl lower than that chosen for analysis.

Explanations for decreased mortality in obese patients admitted to the ICU are unclear. One hypothesis is that obese patients have a lower threshold for ICU admission as compared with normal-weight patients. Consequently, obese patients may have a better prognosis at ICU admission. However, we found that mortality differences were still present and obesity was still associated with protection against in-hospital death after adjusting for APACHE II scores. We are aware that APACHE may be artificially elevated in obesity (increased creatinine levels despite normal renal function, and decreased oxygenation because of lung atelectasis); however, there are no prognostic scores validated for use in the obese critically ill. Cubic spline analysis, which allowed analysis of how

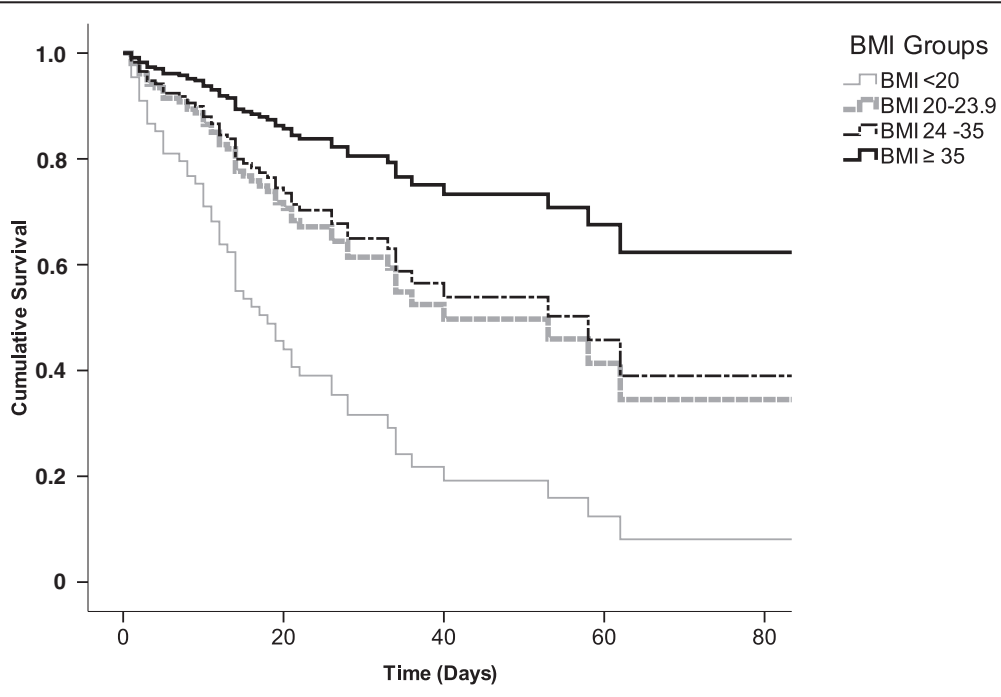

Figure 3 Survival curves stratified by BMI. Kaplan-Meier survival curves stratified by BMI and adjusted for APACHE II scores and $\mathrm{HbA}_{1 \mathrm{c}}$. $\mathrm{BMI}<20$ vs. $20-23.9 \mathrm{~kg} / \mathrm{m}^{2}, P=0.032 ; \mathrm{BMl}<20$ vs. $24-34.9 \mathrm{~kg} / \mathrm{m}^{2}, P=0.010 ; \mathrm{BMl}<20$ vs. $\geq 35 \mathrm{~kg} / \mathrm{m}^{2}, P=0.032$. 
the risk of hospital death varied along the BMI distribution of the study sample, suggests that this relationship is not linear.

However, the high mortality for underweight and lownormal weight patients might be explained by the previous nutrition status, which is a finding more consistent in the literature $[15,30]$, and suggests that special attention to the nutrition of this group of patients is needed.

There are some limitations to this study. First, $\mathrm{HbA}_{1 \mathrm{c}}$ levels were available to all healthcare providers involved in the care of the study patients and whose actions could affect patient management. However, at the study hospital, ICU staff follow a protocol with very well-known targets for acute glycemic control, as proposed in recent guidelines, which do not routinely take $\mathrm{HbA}_{1 \mathrm{c}}$ into account [32]. Second, body size was measured by the team involved in patient care at the ICU, which may have resulted in some variability in body size measurement. Although we did not perform a more sophisticated analysis of body size composition, such as bioelectric impedance, BMI was measured upon admission at ICU, therefore probably reducing the impact of fluid overload in body size determination. Moreover, the staff are well trained in measuring weight and height. Third, few patients had extreme obesity, which hindered quantification of the impact of BMI $>40 \mathrm{~kg} / \mathrm{m}^{2}$ on mortality. However, a recent study suggested no increased risk of mortality in patients with extreme obesity versus those with normal weight [33]. Fourth, we had a high mortality rate, as would be expected for severely ill patients. The expected mortality for our median APACHE II score of 21 is $38 \%$, which was similar to the study overall hospital mortality of $43.2 \%$ [22].

\section{Conclusions}

This study has shown that preexisting hyperglycemia $\left(\mathrm{HbA}_{1 \mathrm{c}}>9.3 \%\right)$ increases the risk of hospital mortality in critically ill patients. Moreover, underweight and lownormal weight patients exhibited a decreased survival rate compared with those who were overweight. Obesity, however, was associated with decreased mortality in critical ill patients. As the prevalence of DM and obesity continue to increase globally, intensivists will require a better understanding of the impact of these conditions in the ICU setting, and will need to develop strategies to improve the care of these patients. Further studies are required for the construction of a strategy for the management of patients with hyperglycemia and obesity in the ICU.

\section{Abbreviations}

APACHE II: Acute physiology chronic health evaluation II; BMI: Body mass index; DM: Diabetes mellitus; $\mathrm{HbA}_{1 c}$ : Glycated hemoglobin; ICU: Intensive care unit; SOFA: Sequential organ failure assessment.

\section{Competing interests}

All authors declare no conflict of interest.

\section{Authors' contributions}

MW had full access to all of the data in the study and takes responsibility for the integrity of the data and the accuracy of the data analysis. Study concept and design: MW, SRV, JLG, and FG. Data collection: MW, RBM, ARF MSF and FG. Data analysis and interpretation: all authors. Manuscript Drafting: all authors; Critical revision of the manuscript for important intellectual content: all authors; Statistical analysis: MV, VBLT, FG. Obtained funding: MW, JLG and FG. All authors read and approved the final manuscript.

\section{Acknowledgments}

Financial support for this study was received from the Fundação de Amparo a Pesquisa do Rio Grande do Sul (FAPERGS), and Fundo de Incentivo a Pesquisa e Eventos do Hospital de Clínicas de Porto Alegre (FIPE-HCPA). We thank the International Scholarship Program of the American Endocrine Society, who provided a scholarship for F.G.

\section{Author details}

${ }^{1}$ Intensive Care Unit, Division of Endocrinology, Hospital de Clínicas de Porto Alegre, Federal University of Rio Grande do Sul, Porto Alegre, Brazil. ²Division of Endocrinology, Hospital de Clínicas de Porto Alegre, Federal University of Rio Grande do Sul, Porto Alegre, Brazil. ${ }^{3}$ Department of Statistics, Federal University of Rio Grande do Sul, and Research and Post-Graduation Group, Hospital de Clínicas de Porto Alegre, Porto Alegre, Brazil.

Received: 12 November 2013 Accepted: 11 June 2014 Published: 17 June 2014

\section{References}

1. Swinburn BA, Sacks G, Hall KD, McPherson K, Finegood DT, Moodie ML, Gortmaker SL: The global obesity pandemic: shaped by global drivers and local environments. Lancet 2011, 378(9793):804-814.

2. Triches C, Schaan BD, Gross JL, Azevedo MJ: Macrovascular diabetic complications: clinical characteristics, diagnosis and management. Arq Bras Endocrinol Metabol 2009, 53(6):698-708.

3. Mokdad AH, Ford ES, Bowman BA, Dietz WH, Vinicor F, Bales VS, Marks JS: Prevalence of obesity, diabetes, and obesity-related health risk factors, 2001. JAMA 2003, 289(1):76-79.

4. Esper AM, Martin GS: The impact of cormorbid conditions on critical illness. Crit Care Med 2011, 39(12):2728-2735.

5. Whitcomb BW, Pradhan EK, Pittas AG, Roghmann MC, Perencevich EN: Impact of admission hyperglycemia on hospital mortality in various intensive care unit populations. Crit Care Med 2005, 33(12):2772-2777.

6. Moore BA, Overhaus M, Whitcomb J, Ifedigbo E, Choi AM, Otterbein LE, Bauer AJ: Brief inhalation of low-dose carbon monoxide protects rodents and swine from postoperative ileus. Crit Care Med 2005, 33(6):1317-1326.

7. Graham BB, Keniston A, Gajic O, Trillo Alvarez CA, Medvedev S, Douglas IS: Diabetes mellitus does not adversely affect outcomes from a critical illness. Crit Care Med 2010, 38(1):16-24.

8. Egi M, Bellomo R, Stachowski E, French CJ, Hart GK, Hegarty C, Bailey M: Blood glucose concentration and outcome of critical illness: the impact of diabetes. Crit Care Med 2008, 36(8):2249-2255.

9. Egi M, Bellomo R, Stachowski E, French CJ, Hart GK, Taori G, Hegarty C, Bailey M: The interaction of chronic and acute glycemia with mortality in critically ill patients with diabetes. Crit Care Med 2011, 39(1):105-111.

10. Cely CM, Arora P, Quartin AA, Kett DH, Schein RM: Relationship of baseline glucose homeostasis to hyperglycemia during medical critical illness. Chest 2004, 126(3):879-887.

11. Position Statement: American Diabetes Association: Diagnosis and classification of diabetes mellitus. Diabetes care 2011, 34(1):S62-S69.

12. Gornik I, Gornik O, Gasparovic V: HbA1c is outcome predictor in diabetic patients with sepsis. Diabetes Res Clin Pract 2007, 77(1):120-125.

13. Slynkova K, Mannino DM, Martin GS, Morehead RS, Doherty DE: The role of body mass index and diabetes in the development of acute organ failure and subsequent mortality in an observational cohort. Critical care 2006, 10(5):R137.

14. Ray DE, Matchett SC, Baker K, Wasser T, Young MJ: The effect of body mass index on patient outcomes in a medical ICU. Chest 2005, 127(6):2125-2131. 
15. Tremblay A, Bandi V: Impact of body mass index on outcomes following critical care. Chest 2003, 123(4):1202-1207.

16. Abhyankar S, Leishear K, Callaghan FM, Demner-Fushman D, McDonald CJ: Lower short- and long-term mortality associated with overweight and obesity in a large cohort study of adult intensive care unit patients. Critical care 2012, 16(6):R235.

17. O'Brien JM Jr, Phillips GS, Ali NA, Lucarelli M, Marsh CB, Lemeshow S: Body mass index is independently associated with hospital mortality in mechanically ventilated adults with acute lung injury. Crit Care Med 2006, 34(3):738-744.

18. Goulenok C, Monchi M, Chiche JD, Mira JP, Dhainaut JF, Cariou A: Influence of overweight on ICU mortality: a prospective study. Chest 2004, 125(4):1441-1445.

19. Bercault N, Boulain T, Kuteifan K, Wolf M, Runge I, Fleury JC: Obesity-related excess mortality rate in an adult intensive care unit: A risk-adjusted matched cohort study. Crit Care Med 2004, 32(4):998-1003.

20. Hogue CW Jr, Stearns JD, Colantuoni E, Robinson KA, Stierer T, Mitter N, Pronovost PJ, Needham DM: The impact of obesity on outcomes after critical illness: a meta-analysis. Intensive Care Med 2009, 35(7):1152-1170.

21. Akinnusi ME, Pineda LA, El Solh AA: Effect of obesity on intensive care morbidity and mortality: a meta-analysis. Crit Care Med 2008, 36(1):151-158,

22. Knaus WA, Draper EA, Wagner DP, Zimmerman JE: APACHE II: a severity of disease classification system. Crit Care Med 1985, 13(10):818-829.

23. Vincent JL, Moreno R, Takala J, Willatts S, De Mendonca A, Bruining H, Reinhart CK, Suter PM, Thijs LG: The SOFA (Sepsis-related Organ Failure Assessment) score to describe organ dysfunction/failure. On behalf of the Working Group on Sepsis-Related Problems of the European Society of Intensive Care Medicine. Intensive Care Med 1996, 22(7):707-710.

24. Consensus $C$ : Consensus statement on the worldwide standardization of the hemoglobin $A_{1 c}$ measurement: the American Diabetes Association, European Association for the Study of Diabetes, International Federation of Clinical Chemistry and Laboratory Medicine, and the International Diabetes Federation. Diabetes Care 2007, 30(9):2399-2400.

25. $\otimes$ : Clinical Guidelines on the Identification, Evaluation, and Treatment of Overweight and Obesity in Adults-The Evidence Report. National Institutes of Health. Obes Res 1998, 6(2):51S-2095.

26. Reinhard F, Douglas N, Stephen S: Tools for spatial data. R package version 6.6.3. [http://cran.r-project.org/web/packages/fields/. Acessed 28 octobre 2013]

27. Heinzl H, Kaider A: Gaining more flexibility in Cox proportional hazards regression models with cubic spline functions. Comput Meth Programs Biomed 1997, 54(3):201-208.

28. Williams BA, Mandrekar JN, Mandrekar SJ, Stephen SC, Alfred FF: Finding optimal cutpoints for continuous covariates with binary and time-to-event outcomes. In Technical Report Series 2000, Volume 79. http://www.mayo.edu/ research/documents/biostat-79pdf/doc-10027230. Acessed 28 octobre 2013.

29. Kavanagh BP, McCowen KC: Clinical practice. Glycemic control in the ICU. New Engl I Tradit Chin Med 2010, 363(26):2540-2546.

30. Oliveros $\mathrm{H}$, Villamor E: Obesity and mortality in critically ill adults: a systematic review and meta-analysis. Obesity 2008, 16(3):515-521.

31. Peake SL, Moran JL, Ghelani DR, Lloyd AJ, Walker MJ: The effect of obesity on 12-month survival following admission to intensive care: a prospective study. Crit Care Med 2006, 34(12):2929-2939.

32. Qaseem A, Humphrey LL, Chou R, Snow V, Shekelle P: Use of intensive insulin therapy for the management of glycemic control in hospitalized patients: a clinical practice guideline from the American College of Physicians. Arch Intern Med 2011, 154(4):260-267.

33. Martino JL, Stapleton RD, Wang M, Day AG, Cahill NE, Dixon AE, Suratt BT, Heyland DK: Extreme obesity and outcomes in critically ill patients. Chest 2011, 140(5):1198-1206

doi:10.1186/1472-6823-14-50

Cite this article as: Viana et al:: Contrasting effects of preexisting hyperglycemia and higher body size on hospital mortality in critically ill patients: a prospective cohort study. BMC Endocrine Disorders 2014 14:50.

\section{Submit your next manuscript to BioMed Central and take full advantage of:}

- Convenient online submission

- Thorough peer review

- No space constraints or color figure charges

- Immediate publication on acceptance

- Inclusion in PubMed, CAS, Scopus and Google Scholar

- Research which is freely available for redistribution

Submit your manuscript at www.biomedcentral.com/submit
() Biomed Central 